Research Article

\title{
Rapid Screening and Quantitative Analysis of 74 Pesticide Residues in Herb by Retention Index Combined with GC-QQQ-MS/MS
}

\author{
Peng Tan $\mathbb{D}^{1,{ }^{1,2}}$ Li Xu, ${ }^{1}$ Xi-Chuan Wei, ${ }^{1}$ Hao-Zhou Huang, ${ }^{1}$ Ding-Kun Zhang ${ }^{1}{ }^{1}$ \\ Chen-Juan Zeng, ${ }^{3}$ Fu-Neng Geng, ${ }^{3}$ Xiao-Ming Bao, ${ }^{4}$ Hua Hua $\mathbb{D}^{,},{ }^{2}$ and Jun-Ning Zhao $\mathbb{D}^{2}$ \\ ${ }^{1}$ College of Pharmacy, Chengdu University of Traditional Chinese Medicine, Chengdu 611137, China \\ ${ }^{2}$ Sichuan Academy of Traditional Chinese Medicine, State Key Laboratory of Quality Evaluation of Traditional Chinese Medicine, \\ Chengdu 610041, China \\ ${ }^{3}$ Sichuan Key Laboratory for Medicinal American Cockroach, Sichuan Good Doctor Panxi Pharmaceutical Co.,Ltd., \\ Chengdu 610000, China \\ ${ }^{4}$ Shimadzu Enterprise Management (China) Co.,Ltd., Chengdu 610023, China
}

Correspondence should be addressed to Ding-Kun Zhang; zhangdingkun@cdutcm.edu.cn, Hua Hua; 905701276@qq.com, and Jun-Ning Zhao; zarmy@189.cn

Received 3 April 2020; Accepted 25 November 2020; Published 16 January 2021

Academic Editor: Krishna K Verma

Copyright (c) 2021 Peng Tan et al. This is an open access article distributed under the Creative Commons Attribution License, which permits unrestricted use, distribution, and reproduction in any medium, provided the original work is properly cited.

In this research, a very practical QuEChERS-GC-MS/MS analytical approach for 74 pesticide residues in herb based on retention index was established. This novel analytical approach has two important technical advantages. One advantage is to quickly screen pesticide compounds in herbs without having to use a large number of pesticide standard substances at the beginning of the experiment. The other advantage is to assist in identifying the target pesticide compound accurately. A total of 74 kinds of pesticides were quickly prescreened in all chuanxiong rhizoma samples. The results showed that three kinds of pesticides were screened out in all the samples, including chlorpyrifos, fipronil, and procymidone, and the three pesticides were qualitatively and quantitatively determined. The RSD values for interday and intraday variation were acquired to evaluate the precision of the analytical approach, and the overall interday and intraday variations are not more than $1.97 \%$ and $3.82 \%$, respectively. The variations of concentrations of the analyzed three pesticide compounds in sample CX16 are $0.74 \%-4.15 \%$, indicating that the three pesticides in the sample solutions were stable in $48 \mathrm{~h}$. The spiked recoveries of the three pesticides are $95.22 \%, 93.03 \%$, and $94.31 \%$, and the RSDs are less than $\pm 6.0 \%$. The methodological verification results indicated the good reliability and accuracy of the new analytical method. This research work is a new application of retention index, and it will be a valuable tool to assist quickly and accurately in the qualitative and quantitative analysis of multipesticide residues in herbs.

\section{Introduction}

With more and more traditional herbal medicines playing an important role in protecting people's health, people are paying more attention to pesticide residues in herbal medicines $[1,2]$. At present, most of the analytical methods for quantitative analysis of multipesticide residues are performed with a gas chromatography-triple quadrupole mass spectrometry (GC-MS/MS) or liquid chromatographytriple quadrupole mass spectrometry (LC-MS/MS) [3-5], which are usually applied to the quantitative determination of multipesticide residues in different fruits [6], honey [7], edible oils [8], tea $[9,10]$, and so on. In addition, there are some simple and novel pesticide residue analysis methods, such as high-performance liquid chromatography [11], multicolor nitrogen dots [12], and bioactive microfluidic paper device [13]. Unfortunately, the rapid screen and quantitative analysis of multipesticide residues in herbal medicines are still facing two very difficult problems. One difficulty is how to rapidly screen out the existing pesticide 
compounds in samples without the standard solution. Usually, a large number of pesticide standard substances were consumed during the quantitative analysis, resulting in high analysis costs. Another difficulty is how to accurately identify the target pesticide compound under the interference from complex chemical components in herbs. Because there are many impurities in herbs that seriously interfere with the target pesticide compounds, which makes it difficult to accurately identify the target pesticide compounds, in particular, some pyrethroid pesticides have optical isomers or cis/transisomers, such as cypermethrin and cyfluthrin, with up to 4 isomers, but it is actually difficult to obtain highpurity standard substances, which make it difficult to accurately identify them. Now, pharmacopoeia standards in many countries strictly require pesticide residue limits in herbal medicines, it is necessary to develop some rapid, highsensitivity, low-cost analysis approach for multipesticide residues in herbs.

In the field of gas chromatography analysis, the retention index is an interesting concept with many important uses [14]. The retention index can assist in identifying target compounds by comparing the experimentally measured retention indices with known indices values $[15,16]$. Now, there are many research reports about the retention index, such as petrochemicals analysis and identification of unknown compounds [17-20]. In the preliminary research of our research group, the retention index has been successfully applied to the analysis of 130 pesticide residues in Panacis quinquefolii radix in order to comply with Hong Kong's drug standards [21].

Chuanxiong rhizoma (Chuanxiong in Chinese) is a very famous traditional herb medicine; it has significant pharmacological effects such as inhibiting platelet activation [22], being anti-inflammatory [23, 24], and protecting brain damage $[25,26]$, which has many clinical applications. However, there are no reports on the multipesticide residues in Chuanxiong. In this study, the principle of the retention index was used to quickly prescreening multipesticide residues in samples without having to use large numbers of pesticide standard substances at the beginning of the experiment and assist accurately in identifying the target pesticide compounds, which provides a valuable analytical approach of multipesticide residues in traditional herbal medicines.

\section{Experimental}

2.1. Chemicals and Materials. During this exemplary application experiment, a total of 74 pesticide standard substances were used to verify the accuracy of the predicted retention times, including 31 different organophosphorus pesticide compounds, 27 different organochlorine pesticide compounds, and 16 different pyrethroid pesticide compounds, used for the quantitative analysis, and all of these pesticide standard substances were purchased from Neochema GmbH (100 $\mu \mathrm{g} / \mathrm{mL}$, Germany). Fenthion- $d 6$ was used as an internal standard compound, purchased from Dr. Ehrenstorfer $\mathrm{GmbH}(100 \mu \mathrm{g} / \mathrm{mL}$, Germany). The mass concentration of $\mathrm{n}$-alkanes mixed standard solution was
$1000 \mathrm{mg} / \mathrm{L}$, purchased from o2si smart solutions company (C9 C33, batch number 110219-06, USA). Acetonitrile and acetic acid for sample solution preparation were HPLC grade (Merck, Germany). QuEChERS extract tubes (batch number 6356241-01) were purchased from Agilent Technologies. All other chemical reagents were purchased from Sigma-Aldrich, China. A total of 40 batches of chuanxiong rhizoma herb samples were collected from Sichuan provinces, China.

2.2. Apparatus and Analytical Conditions. The chromatography assay was performed on a GC-MS/MS TQ8050 system equipped with an auto sample manager (Shimadzu, Japan). The chromatographic separation was performed on a Shimadzu SH-Rxi-5Sil MS column, $30 \mathrm{~m} \times 0.25 \mathrm{~mm} \times 0.25 \mu \mathrm{m}$. The pressure value for high-pressure injection was $250 \mathrm{kPa}$, and the injection port temperature was set to $250^{\circ} \mathrm{C}$; the injection mode was splitless. The high-purity helium was used as a carrier gas. The column flow rate was set to $1.69 \mathrm{~mL} / \mathrm{min}$, the linear velocity was set to $47.2 \mathrm{~cm} / \mathrm{s}$, and the purge flow rate was set to $5 \mathrm{~mL} / \mathrm{min}$. The temperature program of the column was set as follows: maintaining the initial temperature at $50^{\circ} \mathrm{C}$ for 1 minute, first increasing the temperature to $125^{\circ} \mathrm{C}$ at a rate of $25^{\circ} \mathrm{C}$ per minute, then increasing the temperature to $300^{\circ} \mathrm{C}$ at a rate of $10^{\circ} \mathrm{C}$ per minute, and finally holding for 15 minutes; the column equilibration time was set to 2 minutes. The injection volume of each sample test solution was $1.0 \mu \mathrm{L}$. The detector was triple the quadrupole mass spectrometer, the ionization source was electron ionization (EI), the source temperature was set to $230^{\circ} \mathrm{C}$, the high-purity argon was used as collision gas, and the MS transfer line temperature was set to $280^{\circ} \mathrm{C}$. The monitoring mode was set to multiple reaction monitoring (MRM), and all of the monitoring ion pairs and collision energy (CE) were optimized and selected for subsequent analysis (see Table 1). In this experiment, time segmentation detection was applied to increase the analysis sensitivity.

\subsection{Solutions Preparation Procedure}

2.3.1. Preparation of Mixed Standard Stock Solution. Measure accurately appropriate amount of each of the standard stock solutions, dilute with acetonitrile containing $0.05 \%$ acetic acid to prepare solutions containing $100 \mu \mathrm{g} / \mathrm{L}$ and $1000 \mu \mathrm{g} / \mathrm{L}$.

2.3.2. Preparation of Internal Standard Solution. Measure accurately appropriate amount of internal standard stock solution, diluted with acetonitrile to prepare a solution containing $5 \mu \mathrm{g} / \mathrm{mL}$.

\subsubsection{Preparation of Matrix-Matched Standard Solution.} Weigh accurately $3.0 \mathrm{~g}$ of blank sample in sextuplicate, prepare in the same manner of sample test solution till "blowing to $0.4 \mathrm{~mL}$ with nitrogen gas at $40^{\circ} \mathrm{C}$, adding accurately $50 \mu \mathrm{L}, 100 \mu \mathrm{L}$ of mixed standard stock solution 
TABLE 1: Monitoring ion pairs and collision energy of 74 pesticide compounds.

\begin{tabular}{|c|c|c|c|c|c|}
\hline Number & Pesticide name & $m / z 1$ & Collision energy $(\mathrm{V})$ & $m / z 2$ & Collision energy $(\mathrm{V})$ \\
\hline 1 & Dichlorvos & $109.0>79.0$ & 8 & $185.0>93.0$ & 14 \\
\hline 2 & Tecnazene & $260.9>202.9$ & 14 & $202.9>142.9$ & 22 \\
\hline 3 & Diphenylamine & $169.1>66.0$ & 24 & $167.1>139.1$ & 28 \\
\hline 4 & Chlordimeform & $196.0>181.0$ & 10 & $181.0>140.0$ & 15 \\
\hline 5 & Trifluralin & $306.1>264.1$ & 8 & $264.1>160.1$ & 18 \\
\hline 6 & $\alpha-\mathrm{BHC}$ & $180.9>144.9$ & 16 & $218.9>182.9$ & 8 \\
\hline 7 & Hexachlorobenzene & $283.8>248.8$ & 24 & $283.8>213.8$ & 28 \\
\hline 8 & Pentachloroanisole & $264.8>236.8$ & 16 & $279.9>236.8$ & 26 \\
\hline 9 & Dicloran & $206.0>176.0$ & 10 & $176.0>148.0$ & 12 \\
\hline 10 & $\beta-\mathrm{BHC}$ & $180.9>144.9$ & 16 & $218.9>182.9$ & 8 \\
\hline 11 & Quintozene & $264.8>236.8$ & 10 & $294.8>236.8$ & 15 \\
\hline 12 & $\gamma$-BHC & $180.9>144.9$ & 16 & $218.9>182.9$ & 8 \\
\hline 13 & Terbufos & $231.0>128.9$ & 26 & $231.0>174.9$ & 14 \\
\hline 14 & Chlorothalonil & $263.9>168.0$ & 24 & $263.9>228.8$ & 18 \\
\hline 15 & Tefluthrin & $177.0>127.1$ & 16 & $177.0>137.1$ & 16 \\
\hline 16 & $\delta$-BHC & $180.9>144.9$ & 16 & $218.9>182.9$ & 8 \\
\hline 17 & Pentachloraniline & $262.9>191.9$ & 22 & $264.9>193.9$ & 18 \\
\hline 18 & Chlorpyrifos-methyl & $285.9>93.0$ & 22 & $287.9>93.0$ & 22 \\
\hline 19 & Vinclozolin & $212.0>172.0$ & 16 & $285.0>212.0$ & 12 \\
\hline 20 & Parathion-methyl & $263.0>109.0$ & 14 & $125.0>47.0$ & 12 \\
\hline 21 & Heptachlor & $271.8>236.9$ & 20 & $273.8>238.9$ & 16 \\
\hline 22 & Fenchlorphos & $284.9>269.9$ & 16 & $286.9>271.9$ & 18 \\
\hline 23 & Octachlorodipropylether & $130.0>95.0$ & 20 & $181.0>85.0$ & 10 \\
\hline 24 & Fenitrothion & $283.1>115.0$ & 18 & $283.1>131.0$ & 18 \\
\hline 25 & Methyl-pentachlorophenyl sulfide & $295.8>262.9$ & 14 & $295.8>245.8$ & 30 \\
\hline 26 & Dichlofluanid & $223.9>123.1$ & 8 & $167.1>124.1$ & 10 \\
\hline 27 & Chlorpyrifos & $196.9>168.9$ & 14 & $313.9>257.9$ & 14 \\
\hline 28 & Aldrin & $262.9>191.0$ & 34 & $262.9>193.0$ & 28 \\
\hline 29 & Fenthion-d6 & $284.0>115.0$ & 20 & $284.0>169.0$ & 15 \\
\hline 30 & Chlorthal-dimethyl & $298.9>220.9$ & 24 & $300.9>222.9$ & 26 \\
\hline 31 & Parathion-ethyl & $139.0>109.0$ & 8 & $291.1>109.0$ & 14 \\
\hline 32 & Triadimefon & $208.1>181.0$ & 10 & $208.1>111.0$ & 22 \\
\hline 33 & Dicofol & $139.0>111.0$ & 16 & $139.0>75.0$ & 28 \\
\hline 34 & Butralin & $266.1>190.1$ & 12 & $266.1>236.1$ & 8 \\
\hline 35 & Bromophos-methyl & $330.9>315.9$ & 14 & $328.9>313.9$ & 18 \\
\hline 36 & Pendimethalin & $252.1>162.1$ & 10 & $252.1>191.1$ & 8 \\
\hline 37 & Fipronil & $366.9>212.9$ & 30 & $368.9>214.9$ & 30 \\
\hline 38 & Heptachlor exo-epoxide & $352.8>262.9$ & 14 & $354.8>264.9$ & 20 \\
\hline 39 & Chlordane-oxy & $185.0>149.0$ & 6 & $185.0>121.0$ & 12 \\
\hline 40 & Heptachlor endo-epoxide & $352.8>253.0$ & 26 & $354.8>253.0$ & 18 \\
\hline 41 & Dimepiperate & $119.1>91.1$ & 10 & $145.1>112.1$ & 8 \\
\hline 42 & Procymidone & $283.0>96.0$ & 10 & $285.0>96.0$ & 10 \\
\hline 43 & Triadimenol-1 & $168.1>70.0$ & 10 & $128.1>65.0$ & 22 \\
\hline 44 & Triadimenol-2 & $168.1>70.0$ & 10 & $128.1>65.0$ & 22 \\
\hline 45 & Bromophos-ethyl & $358.9>302.9$ & 16 & $302.9>284.9$ & 18 \\
\hline 46 & Chlordane-trans & $374.8>265.9$ & 26 & $372.8>263.9$ & 28 \\
\hline 47 & o, p'-DDE & $246.0>176.0$ & 30 & $248.0>176.0$ & 28 \\
\hline 48 & Flumetralin & $143.0>107.0$ & 21 & $143.0>83.0$ & 18 \\
\hline 49 & Chlordane-cis & $374.8>265.9$ & 26 & $372.8>263.9$ & 28 \\
\hline 50 & $\alpha$-Endosulfan & $194.9>160.0$ & 8 & $194.9>125.0$ & 24 \\
\hline 51 & $\mathrm{p}, \mathrm{p}^{\prime}-\mathrm{DDE}$ & $246.0>176.0$ & 30 & $317.9>248.0$ & 24 \\
\hline 52 & Dieldrin & $276.9>241.0$ & 8 & $262.9>193.0$ & 34 \\
\hline 53 & o, p'-DDD & $235.0>165.0$ & 24 & $237.0>165.0$ & 28 \\
\hline 54 & Chlorfenapyr & $247.1>227.0$ & 16 & $139.0>102.0$ & 12 \\
\hline 55 & Nitrofen & $202.0>139.0$ & 24 & $282.9>253.0$ & 12 \\
\hline 56 & Endrin & $262.9>191.0$ & 30 & $262.9>193.0$ & 28 \\
\hline 57 & $\beta$-Endosulfan & $194.9>160.0$ & 8 & $194.9>125.0$ & 24 \\
\hline 58 & $\mathrm{p}, \mathrm{p}^{\prime}-\mathrm{DDD}$ & $235.0>165.0$ & 24 & $237.0>165.0$ & 28 \\
\hline 59 & $\mathrm{o}, \mathrm{p}^{\prime}-\mathrm{DDT}$ & $235.0>165.0$ & 24 & $237.0>165.0$ & 28 \\
\hline 60 & Endosulfan sulfate & $271.8>236.9$ & 18 & $386.8>252.9$ & 16 \\
\hline
\end{tabular}


TABle 1: Continued.

\begin{tabular}{|c|c|c|c|c|c|}
\hline Number & Pesticide name & $m / z 1$ & Collision energy (V) & $m / z 2$ & Collision energy $(\mathrm{V})$ \\
\hline 61 & $\mathrm{p}, \mathrm{p}^{\prime}-\mathrm{DDT}$ & $235.0>165.0$ & 24 & $237.0>165.0$ & 28 \\
\hline 62 & Bifenthrin & $181.1>166.1$ & 12 & $181.1>179.1$ & 12 \\
\hline 63 & Bromopropylate & $340.9>182.9$ & 18 & $340.9>184.9$ & 20 \\
\hline 64 & Methoxychlor & $227.1>169.1$ & 24 & $227.1>212.1$ & 14 \\
\hline 65 & Fenpropathrin & $181.1>152.1$ & 22 & $265.1>210.1$ & 12 \\
\hline 66 & Phenothrin-1 & $123.1>81.0$ & 8 & $183.1>153.1$ & 14 \\
\hline 67 & Phenothrin-2 & $123.1>81.0$ & 8 & $183.1>153.1$ & 14 \\
\hline 68 & Cyhalothrin-1 & $208.0>181.0$ & 8 & $197.0>141.0$ & 12 \\
\hline 69 & Acrinathrin & $181.1>152.1$ & 26 & $289.1>93.0$ & 14 \\
\hline 70 & Cyhalothrin-2 & $208.0>181.0$ & 8 & $197.0>141.0$ & 12 \\
\hline 71 & Mirex & $271.8>236.8$ & 18 & $273.8>238.8$ & 18 \\
\hline 72 & Acrinathrin-2 & $181.1>152.1$ & 26 & $289.1>93.0$ & 14 \\
\hline 73 & Permethrin-1 & $183.1>153.1$ & 14 & $183.1>168.1$ & 14 \\
\hline 74 & Permethrin-2 & $183.1>153.1$ & 14 & $183.1>168.1$ & 14 \\
\hline 75 & Cyfluthrin-1 & $163.1>127.1$ & 6 & $163.1>91.0$ & 14 \\
\hline 76 & Cyfluthrin-2 & $163.1>127.1$ & 6 & $163.1>91.0$ & 14 \\
\hline 77 & Cyfluthrin-3 & $163.1>127.1$ & 6 & $163.1>91.0$ & 14 \\
\hline 78 & Cyfluthrin-4 & $163.1>127.1$ & 6 & $163.1>91.0$ & 14 \\
\hline 79 & Cypermethrin-1 & $163.1>127.1$ & 6 & $163.1>91.0$ & 14 \\
\hline 80 & Cypermethrin-2 & $163.1>127.1$ & 6 & $163.1>91.0$ & 14 \\
\hline 81 & Cypermethrin-3 & $163.1>127.1$ & 6 & $163.1>91.0$ & 14 \\
\hline 82 & Flucythrinate-1 & $199.1>157.1$ & 10 & $157.1>107.1$ & 12 \\
\hline 83 & Quizalofop-ethyl & $372.1>299.1$ & 14 & $299.1>255.1$ & 18 \\
\hline 84 & Cypermethrin-4 & $163.1>127.1$ & 6 & $163.1>91.0$ & 14 \\
\hline 85 & Flucythrinate- 2 & $199.1>157.1$ & 10 & $157.1>107.1$ & 12 \\
\hline 86 & Fenvalerate-1 & $225.1>119.1$ & 20 & $225.1>147.1$ & 10 \\
\hline 87 & Fenvalerate-2 & $225.1>119.1$ & 20 & $225.1>147.1$ & 10 \\
\hline 88 & Deltamethrin-1 & $180.9>151.9$ & 22 & $252.9>93.0$ & 20 \\
\hline 89 & Deltamethrin-2 & $180.9>151.9$ & 22 & $252.9>93.0$ & 20 \\
\hline
\end{tabular}

Compound 29 is internal standard compound. Some pesticides have multiple retention times because of isomers.

$(100 \mu \mathrm{g} / \mathrm{L})$ and $50 \mu \mathrm{L}, 100 \mu \mathrm{L}, 200 \mu \mathrm{L}, 400 \mu \mathrm{L}$ of mixed standard stock solution $(1000 \mu \mathrm{g} / \mathrm{L})$ " [21], and dilute to $1 \mathrm{~mL}$ with acetonitrile, vortex, and filter $(0.22 \mu \mathrm{m})$.

2.3.4. Preparation of Sample Test Solution. Prepare the sample solution according to the QuEChERS operating procedures and literature report [21].

2.4. Samples Assay Procedure. Firstly, the GC-MS/MS system automatically and accurately absorbed $1.0 \mu \mathrm{L}(5.0 \mu \mathrm{g} / \mathrm{mL})$ of n-alkanes C9 C33 mixed standard solution for analysis under the given monitoring conditions, and then we have confirmed that all chromatographic peaks of $\mathrm{C} 9 \sim \mathrm{C} 33$ were correct; next, according to the retention indexes and retention times in the Smart Pesticides Database, the GC-MS/MS system automatically calculated the all predicted retention times of 74 target pesticide compounds. Then, the GC-MS/MS system automatically absorbed $1.0 \mu \mathrm{L}$ of each sample test solution and injected them into the GC-MS/MS for analysis. According to the experimental results, we prescreened which pesticides are contained in all samples using mass-to-charge ratios $(\mathrm{m} / \mathrm{z})$ and predicted retention times. Finally, we have prepared a mixed standard solution containing these screened out pesticides for targeted quantitative determination using the internal standard curve method.
2.5. Method Validation. The purpose of the validation of an analytical method is to ensure that the adopted method meets the requirements of the intended analytical applications. This newly established method was carried out in accordance with the international conference on harmonization guidelines ( $\mathrm{ICH}$ Q2B, validation of analytical procedures, methodology).

2.5.1. Precision. Intermediate-precision and repeatability were designed to evaluate the effect of random variable factors on precision. The variable factors include different dates and different analysts. The relative standard deviation (RSD) was used to evaluate the variation range of the results. Intraday and interday repeatability was determined by sixreplicate analyses of sample CX16 within one and two consecutive days, respectively. In a specified range, use results from 6 test samples at the same concentration to evaluate the repeatability of the precision study.

2.5.2. Linearity. The linearity of this new analytical method is its ability to elicit test results that are directly proportional to the concentration of the analyte in samples within a given range. The samples with varying concentrations of analytes for linearity determination are prepared by diluting accurately a stock solution. During the experiment, 6 portions of sample solutions were prepared. The regression equation 
and correlation coefficient were used to evaluate the correlation between the peak area $(y)$ and the injection mass concentration $(x, \mu \mathrm{g} / \mathrm{L})$ of each pesticide compound.

2.5.3. Sensitivity. The limit of detection (LOD) was defined as the lowest mass concentration of each pesticide compound resulting in a signal-to-noise ratio of $3: 1$. The limit of quantification (LOQ) was defined as the lowest mass concentration of each pesticide compound resulting in a signalto-noise ratio of $10: 1$.

2.5.4. Extraction Accuracy. Accuracy was usually represented as percent recovery and was determined in the specified range. High-purity standard substances were used for the analysis of the recovery of the added sample. In this experiment, a certain number of the standard substances of the test substances were precisely added into the test sample with known content of analyte to be examined. The recovery ratio was calculated by the margin of the determined value and the number of the substances being examined divided by the number of the added standard substances:

$$
\text { recovery }(\%)=\frac{(C-A)}{B} \times 100 \% \text {, }
$$

where $A$ is the amount of the analyte in the substance being examined; $B$ is the amount of the added standard substance; and $C$ is the determined value.

2.5.5. Stability. The stability of the analyzed pesticide compounds in the sample solution was detected by analyzing sample CX16, and the peak areas of the analyzed pesticide compounds at $0,2,4,8,24$, and $48 \mathrm{~h}$ were recorded. Variations in the content were expressed as RSD values.

\section{Results and Discussion}

3.1. Obtained Predicted Retention Times by Retention Indexes of n-Alkanes C9 C33. Experiment results showed that the first target pesticide compound was detected at 6 minutes (dichlorvos), and the last target pesticide compound was detected at 22 minutes (deltamethrin-2). The actual measured retention indexes of 74 target pesticide compounds are displayed in Table 2, and as shown, there is a small difference between the actual measured retention indexes and the original retention indexes listed in the Smart Pesticides Database. At the same time, the predicted retention times of 74 target pesticides were obtained by actual measured retention indexes of 74 pesticide compounds combined with the Smart Pesticides Database (see Table 2). The schematic diagram of predicting retention time of target pesticide using retention index principle is displayed Figure 1. The typical total ionic chromatogram of C9 C33 mixed standard solution is displayed in Figure 2.

3.2. Verification Accuracy of the Predicted Retention Times Using Standard Substances. In order to verify the accuracy of the predicted retention times, a mixed standard substances solution containing 74 pesticide standard substances was analyzed under the same analysis conditions. The results showed that all the predicted retention times were very close to the actual measured retention times; it was worth noting that all the times deviations were within $0.02 \mathrm{~min}$, and this means that these predicted retention times were very accurate. The detailed data are summarized and displayed in Table 2.

3.3. Rapid Prescreening 74 Pesticide Compounds Using Predicted Retention Times. One important application of the predicted retention times was to quickly screen out pesticide compounds in herbs without having to use a large number of pesticide standard substances at the beginning of the experiment. All 40 batches of chuanxiong rhizoma samples have been quickly screened using the predicted retention times of 74 target pesticides and mass-to-charge ratios. The prescreened results showed that all samples only contained three different pesticide compounds, including chlorpyrifos, fipronil, and procymidone. Because this experiment was an exemplary research, in order to confirm the accuracy of the screening results, 74 pesticide standard substances were used to verify the accuracy of the screening results. The confirmation results also showed that all samples contained the three pesticides. Next, it was very simple and convenient to quantitatively analyze the three pesticide compounds that have been screened out. More importantly, this experiment has demonstrated that the predicted retention time obtained by the retention index principle could be used to screen out pesticides in herbs without having to use large amounts of pesticide standard substances.

3.4. Assist in Identifying Target Pesticide Compounds Using Predicted Retention Times. Another practical and important application of the predicted retention time was to assist accurately in identifying the target pesticide compound when the target pesticide compound was seriously disturbed. In cases where the mass spectrometry system cannot automatically identify or misidentify them, the predicted retention time of the target pesticide compound can be referenced to help in the qualitative analysis. Taking cypermethrin-3 as an example, we want to accurately identify and qualify cypermethrin-3 in mass chromatogram, but cypermethrin- 2 and cypermethrin- 4 were also located near cypermethrin-3, the actual measured retention times of the three isomers were $20.561,20.663$, and $20.717 \mathrm{~min}$, the predicted retention times of the three isomers were 20.557, 20.662, and $20.711 \mathrm{~min}$, and the deviations were 0.004, 0.001, and $0.006 \mathrm{~min}$, respectively. When the mass spectrometry system could not accurately identify cypermethrin-3 automatically, or in the absence of a cypermethrin-3 monomer standard solution, the predicted retention times of the three isomers of cypermethrin were very useful and could assist in identifying cypermethrin-3, the detailed information is displayed in Figure 3 and Table 2. This analytical approach can assist in identifying other difficult-to-identify target pesticide compounds. 
TABLE 2: Results of the predicted retention times and the actual measured retention times.

\begin{tabular}{|c|c|c|c|c|c|c|}
\hline Number & Pesticide name & $\begin{array}{l}\text { Retention index } \\
\text { from the database }\end{array}$ & $\begin{array}{c}\text { Predicted } \\
\text { retention time } \\
(\mathrm{min})\end{array}$ & $\begin{array}{l}\text { Actual measured } \\
\text { retention index }\end{array}$ & $\begin{array}{l}\text { Actual measured } \\
\text { retention time } \\
(\mathrm{min})\end{array}$ & $\begin{array}{l}\text { Time deviation } \\
\text { value (min) }\end{array}$ \\
\hline 1 & Dichlorvos & 1248 & 6.023 & 1244 & 6.017 & 0.006 \\
\hline 2 & Tecnazene & 1595 & 9.618 & 1597 & 9.621 & 0.003 \\
\hline 3 & Diphenylamine & 1631 & 10.007 & 1592 & 10.001 & 0.006 \\
\hline 4 & Chlordimeform & 1660 & 10.319 & 1661 & 10.323 & 0.004 \\
\hline 5 & Trifluralin & 1666 & 10.384 & 1666 & 10.380 & 0.004 \\
\hline 6 & $\alpha-\mathrm{BHC}$ & 1705 & 10.803 & 1707 & 10.820 & 0.017 \\
\hline 7 & Hexachlorobenzene & 1710 & 10.856 & 1709 & 10.843 & 0.013 \\
\hline 8 & Pentachloroanisole & 1723 & 10.993 & 1725 & 11.009 & 0.016 \\
\hline 9 & Dicloran & 1731 & 11.077 & 1731 & 11.081 & 0.004 \\
\hline 10 & $\beta$-BHC & 1755 & 11.329 & 1755 & 11.328 & 0.001 \\
\hline 11 & Quintozene & 1759 & 11.371 & 1763 & 11.373 & 0.002 \\
\hline 12 & Lindane & 1769 & 11.476 & 1755 & 11.468 & 0.008 \\
\hline 13 & Terbufos & 1778 & 11.571 & 1778 & 11.571 & 0.000 \\
\hline 14 & Chlorothalonil & 1803 & 11.833 & 1803 & 11.835 & 0.002 \\
\hline 15 & Tefluthrin & 1819 & 11.996 & 1818 & 11.982 & 0.014 \\
\hline 16 & $\delta$-BHC & 1825 & 12.057 & 1825 & 12.055 & 0.002 \\
\hline 17 & Pentachloraniline & 1855 & 12.363 & 1858 & 12.378 & 0.015 \\
\hline 18 & Chlorpyrifos-methyl & 1882 & 12.638 & 1883 & 12.653 & 0.015 \\
\hline 19 & Vinclozolin & 1891 & 12.730 & 1857 & 12.712 & 0.018 \\
\hline 20 & Parathion-methyl & 1896 & 12.781 & 1895 & 12.770 & 0.011 \\
\hline 21 & Heptachlor & 1909 & 12.910 & 1915 & 12.927 & 0.017 \\
\hline 22 & Fenchlorphos & 1916 & 12.979 & 1918 & 12.995 & 0.016 \\
\hline 23 & Octachlorodipropylether & 1932 & 13.136 & 1932 & 13.140 & 0.004 \\
\hline 24 & Fenitrothion & 1946 & 13.273 & 1945 & 13.267 & 0.006 \\
\hline 25 & $\begin{array}{l}\text { Methyl-pentachlorophenyl } \\
\text { sulfide }\end{array}$ & 1954 & 13.351 & 1957 & 13.365 & 0.014 \\
\hline 26 & Dichlofluanid & 1959 & 13.400 & 1960 & 13.410 & 0.010 \\
\hline 27 & Chlorpyrifos & 1977 & 13.577 & 1978 & 13.583 & 0.006 \\
\hline 28 & Aldrin & 1981 & 13.601 & 1964 & 13.595 & 0.006 \\
\hline 29 & Fenthion-d6 & 1982 & 13.626 & 1981 & 13.616 & 0.010 \\
\hline 30 & Chlorthal-dimethyl & 1986 & 13.665 & 1988 & 13.677 & 0.012 \\
\hline 31 & Parathion-ethyl & 1993 & 13.734 & 1993 & 13.730 & 0.004 \\
\hline 32 & Triadimefon & 1999 & 13.793 & 1999 & 13.793 & 0.000 \\
\hline 33 & Dicofol & 2008 & 13.878 & 2009 & 13.889 & 0.011 \\
\hline 34 & Butralin & 2012 & 13.935 & 2014 & 13.938 & 0.003 \\
\hline 35 & Bromophos-methyl & 2021 & 14.012 & 2023 & 14.018 & 0.006 \\
\hline 36 & Pendimethalin & 2044 & 14.227 & 2046 & 14.232 & 0.005 \\
\hline 37 & Fipronil & 2055 & 14.321 & 2054 & 14.314 & 0.007 \\
\hline 38 & Heptachlor exo-epoxide & 2061 & 14.397 & 2067 & 14.401 & 0.004 \\
\hline 39 & Chlordane-oxy & 2061 & 14.398 & 2067 & 14.409 & 0.011 \\
\hline 40 & Heptachlor endo-epoxide & 2069 & 14.453 & 2075 & 14.468 & 0.015 \\
\hline 41 & Dimepiperate & 2086 & 14.613 & 2087 & 14.622 & 0.009 \\
\hline 42 & Procymidone & 2086 & 14.613 & 2086 & 14.617 & 0.004 \\
\hline 43 & Triadimenol-1 & 2087 & 14.622 & 2086 & 14.617 & 0.005 \\
\hline 44 & Triadimenol-2 & 2103 & 14.772 & 2103 & 14.768 & 0.004 \\
\hline 45 & Bromophos-ethyl & 2106 & 14.799 & 2109 & 14.812 & 0.013 \\
\hline 46 & Chlordane-trans & 2110 & 14.835 & 2108 & 14.817 & 0.018 \\
\hline 47 & o, p'-DDE & 2116 & 14.889 & 2120 & 14.905 & 0.016 \\
\hline 48 & Flumetralin & 2127 & 14.989 & 2128 & 14.994 & 0.005 \\
\hline 49 & Chlordane-cis & 2137 & 15.079 & 2144 & 15.081 & 0.002 \\
\hline 50 & $\alpha$-Endosulfan & 2139 & 15.098 & 2144 & 15.105 & 0.007 \\
\hline 51 & $\mathrm{p}, \mathrm{p}$-DDE & 2185 & 15.514 & 2188 & 15.524 & 0.010 \\
\hline 52 & Dieldrin & 2195 & 15.604 & 2175 & 15.601 & 0.003 \\
\hline 53 & o, p'-DDD & 2199 & 15.640 & 2224 & 15.655 & 0.015 \\
\hline 54 & Chlorfenapyr & 2222 & 15.841 & 2222 & 15.837 & 0.004 \\
\hline 55 & Nitrofen & 2239 & 15.969 & 2213 & 15.965 & 0.004 \\
\hline 56 & Endrin & 2240 & 15.997 & 2247 & 16.011 & 0.014 \\
\hline 57 & $\beta$-Endosulfan & 2266 & 16.223 & 2270 & 16.239 & 0.016 \\
\hline
\end{tabular}


TABLE 2: Continued.

\begin{tabular}{|c|c|c|c|c|c|c|}
\hline Number & Pesticide name & $\begin{array}{l}\text { Retention index } \\
\text { from the database }\end{array}$ & $\begin{array}{l}\text { Predicted } \\
\text { retention time } \\
(\mathrm{min})\end{array}$ & $\begin{array}{l}\text { Actual measured } \\
\text { retention index }\end{array}$ & $\begin{array}{l}\text { Actual measured } \\
\text { retention time } \\
(\mathrm{min})\end{array}$ & $\begin{array}{l}\text { Time deviation } \\
\text { value (min) }\end{array}$ \\
\hline 58 & $\mathrm{p}, \mathrm{p}^{\prime}-\mathrm{DDD}$ & 2276 & 16.310 & 2299 & 16.312 & 0.002 \\
\hline 59 & $o, p^{\prime}-D D T$ & 2280 & 16.345 & 2259 & 16.361 & 0.016 \\
\hline 60 & Endosulfan sulfate & 2351 & 16.945 & 2355 & 16.958 & 0.013 \\
\hline 61 & $\mathrm{p}, \mathrm{p}$-DDT & 2359 & 17.032 & 2364 & 17.040 & 0.008 \\
\hline 62 & Bifenthrin & 2469 & 17.909 & 2469 & 17.908 & 0.001 \\
\hline 63 & Bromopropylate & 2475 & 17.957 & 2438 & 17.951 & 0.006 \\
\hline 64 & Methoxychlor & 2487 & 18.043 & 2460 & 18.036 & 0.007 \\
\hline 65 & Fenpropathrin & 2493 & 18.101 & 2492 & 18.096 & 0.005 \\
\hline 66 & Phenothrin-1 & 2526 & 18.359 & 2526 & 18.362 & 0.003 \\
\hline 67 & Phenothrin-2 & 2540 & 18.467 & 2541 & 18.473 & 0.006 \\
\hline 68 & Cyhalothrin-1 & 2573 & 18.722 & 2572 & 18.713 & 0.009 \\
\hline 69 & Acrinathrin & 2591 & 18.861 & 2595 & 18.871 & 0.010 \\
\hline 70 & Cyhalothrin-2 & 2595 & 18.892 & 2595 & 18.891 & 0.001 \\
\hline 71 & Mirex & 2610 & 19.005 & 2615 & 19.014 & 0.009 \\
\hline 72 & Acrinathrin-2 & 2619 & 19.062 & 2616 & 19.052 & 0.010 \\
\hline 73 & Permethrin-1 & 2702 & 19.696 & 2703 & 19.701 & 0.005 \\
\hline 74 & Permethrin-2 & 2720 & 19.821 & 2721 & 19.828 & 0.007 \\
\hline 75 & Cyfluthrin-1 & 2777 & 20.232 & 2778 & 20.236 & 0.004 \\
\hline 76 & Cyfluthrin-2 & 2791 & 20.333 & 2791 & 20.334 & 0.001 \\
\hline 77 & Cyfluthrin-3 & 2799 & 20.390 & 2800 & 20.395 & 0.005 \\
\hline 78 & Cyfluthrin-4 & 2806 & 20.439 & 2806 & 20.439 & 0.000 \\
\hline 79 & Cypermethrin-1 & 2823 & 20.557 & 2824 & 20.561 & 0.004 \\
\hline 80 & Cypermethrin-2 & 2838 & 20.662 & 2824 & 20.663 & 0.001 \\
\hline 81 & Cypermethrin-3 & 2845 & 20.711 & 2847 & 20.717 & 0.006 \\
\hline 82 & Flucythrinate-1 & 2847 & 20.724 & 2847 & 20.726 & 0.002 \\
\hline 83 & Quizalofop-ethy-l & 2848 & 20.743 & 2851 & 20.751 & 0.008 \\
\hline 84 & Cypermethrin-4 & 2852 & 20.759 & 2852 & 20.762 & 0.003 \\
\hline 85 & Flucythrinate-2 & 2875 & 20.919 & 2875 & 20.922 & 0.003 \\
\hline 86 & Fenvalerate-1 & 2951 & 21.442 & 2930 & 21.448 & 0.006 \\
\hline 87 & Fenvalerate-2 & 2981 & 21.628 & 2930 & 21.619 & 0.009 \\
\hline 88 & Deltamethrin-1 & 3031 & 22.016 & 3034 & 22.024 & 0.008 \\
\hline 89 & Deltamethrin-2 & 3060 & 22.235 & 3063 & 22.242 & 0.007 \\
\hline
\end{tabular}

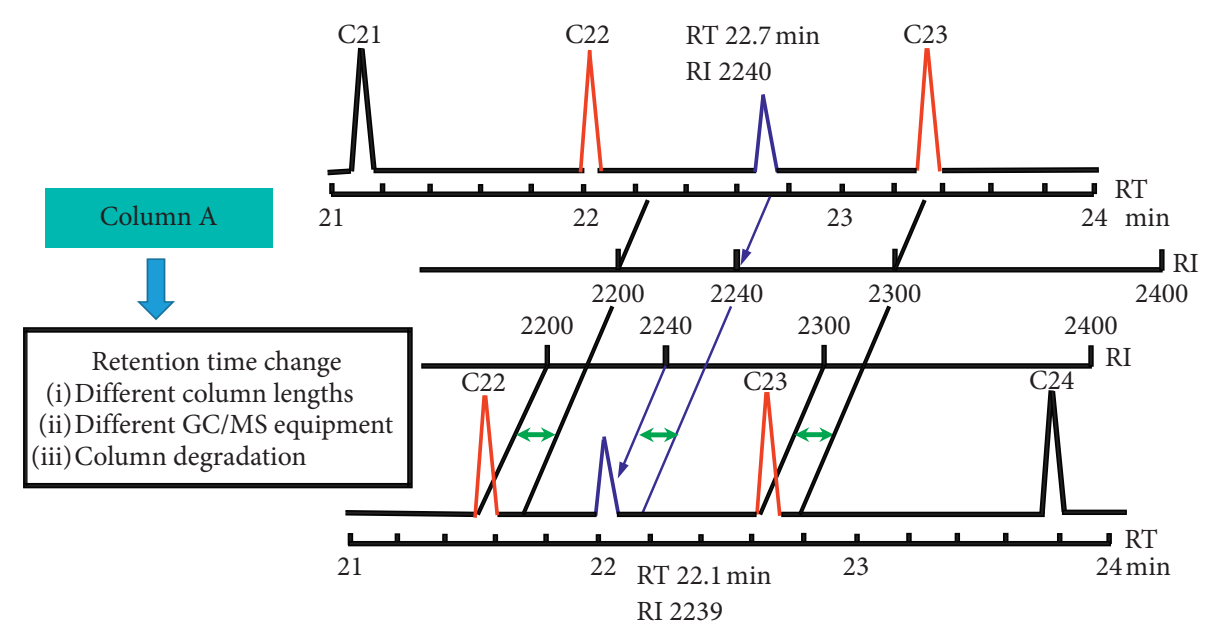

FIGURE 1: Schematic diagram of predicting retention time of target pesticide using retention index principle.

3.5. Samples Assay Result. The developed GC-MS/MS analytical method was applied to quickly screen out and assist in the quantitative determination of the multipesticide residues in chuanxiong rhizoma samples; the identification of all pesticide compounds was based on mass-to-charge ratios and predicted retention times. The quick screening results showed all the samples containing three different pesticide compounds, including chlorpyrifos, fipronil, and procymidone. 


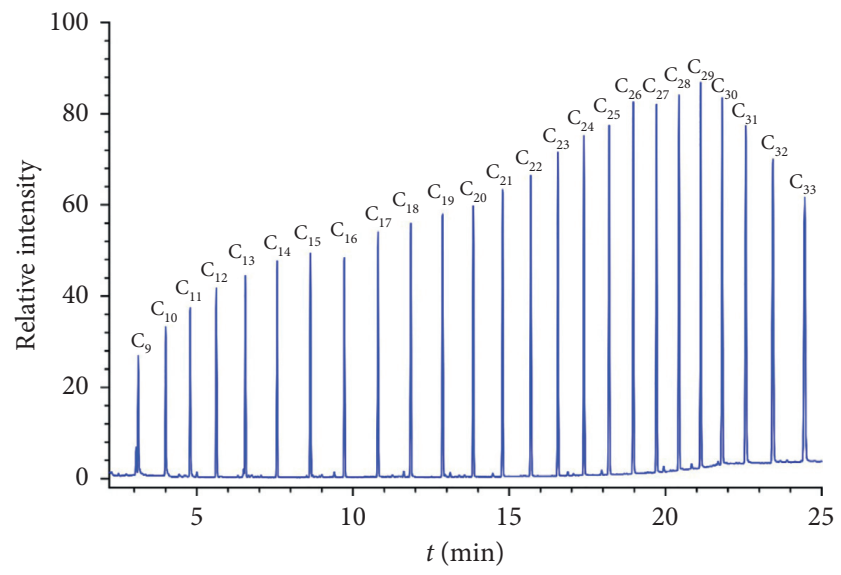

Figure 2: Typical total ionic chromatogram (TIC) of n-alkanes C9 C33 mixed standard solution.

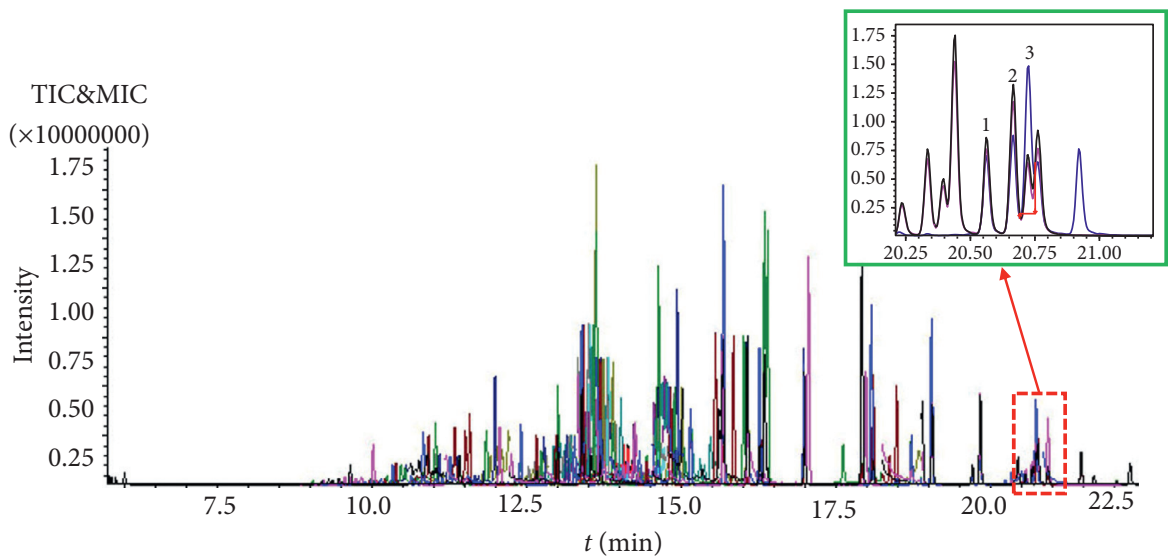

Figure 3: Typical total ionic chromatogram of mixed chuanxiong rhizoma sample solution containing 74 pesticide standard substances $(200 \mu \mathrm{g} / \mathrm{L})$.

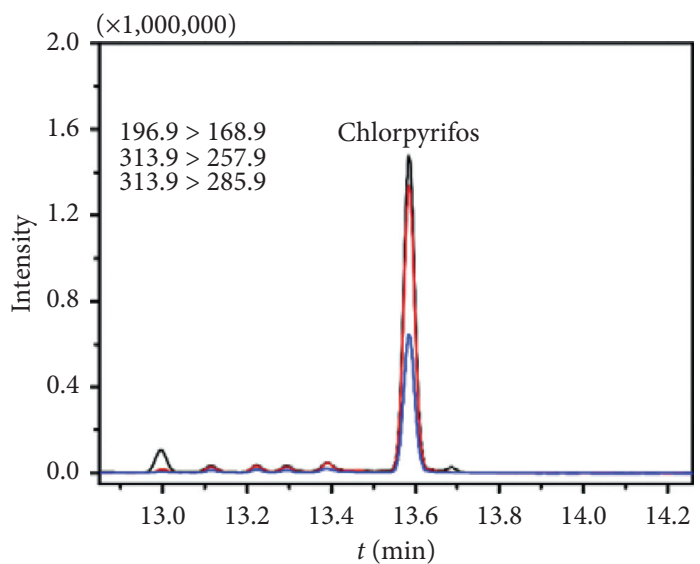

(a)

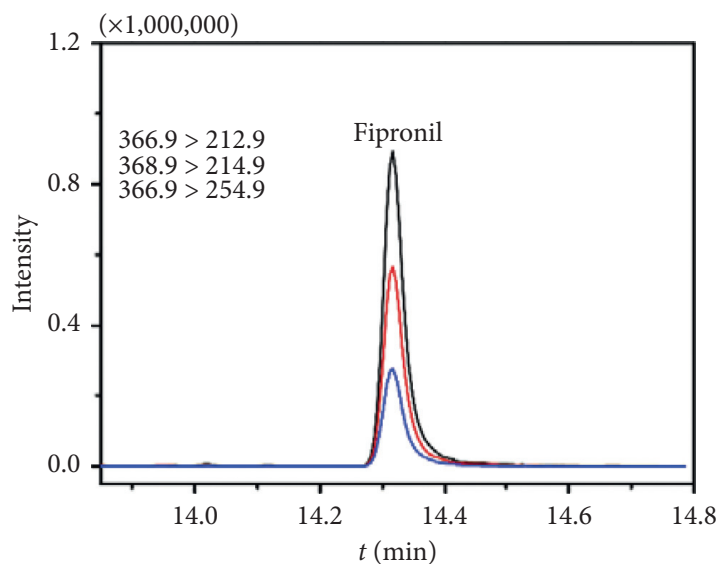

(b)

Figure 4: Continued. 


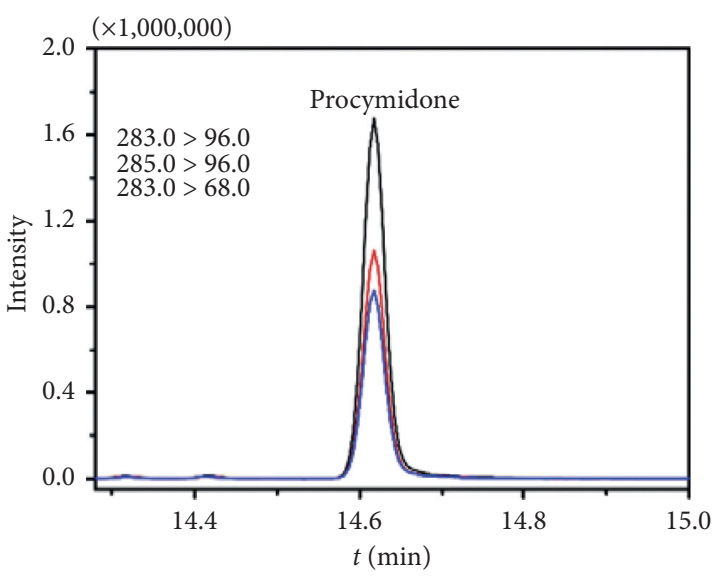

(c)

FigURE 4: Typical mass chromatograms of chlorpyrifos, fipronil, and procymidone in chuanxiong rhizoma sample.

TABLE 3: Targeted quantitative analysis results of three pesticides in 40 batches of samples (mean, $\mu \mathrm{g} / \mathrm{kg}$ ).

\begin{tabular}{|c|c|c|c|}
\hline Samples & Procymidone & Chlorpyrifos & Fipronil \\
\hline CX01 & 94.77 & ND & ND \\
\hline CX02 & 47.11 & ND & ND \\
\hline CX03 & 60.75 & ND & ND \\
\hline CX04 & 42.89 & ND & ND \\
\hline CX05 & 29.91 & ND & ND \\
\hline CX06 & 71.73 & ND & ND \\
\hline CX07 & 49.85 & ND & ND \\
\hline CX08 & 31.75 & ND & ND \\
\hline CX09 & ND & 485.92 & ND \\
\hline CX10 & 28.25 & ND & ND \\
\hline CX11 & 56.13 & ND & ND \\
\hline CX12 & 56.95 & $\mathrm{ND}$ & ND \\
\hline CX13 & 2841.54 & ND & ND \\
\hline CX14 & ND & ND & ND \\
\hline CX15 & 69.50 & ND & ND \\
\hline CX16 & 159.29 & ND & ND \\
\hline CX17 & 35.61 & ND & ND \\
\hline CX18 & ND & ND & 28.62 \\
\hline CX19 & 3712.16 & ND & ND \\
\hline CX20 & 77.30 & ND & ND \\
\hline $\mathrm{CX} 21$ & 64.58 & $\mathrm{ND}$ & ND \\
\hline CX22 & ND & ND & 193.12 \\
\hline CX23 & ND & ND & ND \\
\hline $\mathrm{CX} 24$ & 61.62 & ND & 38.28 \\
\hline CX25 & 44.16 & ND & ND \\
\hline CX26 & 77.72 & ND & $\mathrm{ND}$ \\
\hline CX27 & ND & ND & 64.21 \\
\hline CX28 & 71.27 & ND & ND \\
\hline CX29 & ND & $\mathrm{ND}$ & ND \\
\hline CX30 & 142.19 & ND & ND \\
\hline CX31 & 66.31 & ND & ND \\
\hline CX32 & 81.09 & ND & ND \\
\hline CX33 & ND & ND & ND \\
\hline CX34 & ND & ND & ND \\
\hline CX35 & 57.36 & ND & ND \\
\hline CX36 & 82.61 & ND & ND \\
\hline CX37 & ND & ND & ND \\
\hline CX38 & ND & ND & ND \\
\hline CX39 & 85.36 & ND & ND \\
\hline CX40 & 96.77 & ND & ND \\
\hline
\end{tabular}

ND represents that the limit of detection has not been reached. 
TABLE 4: Results of methodological verification $(n=6)$.

\begin{tabular}{lcccccc}
\hline Pesticides & Linear regression equation & $R^{2}$ & LOD $(\mu \mathrm{g} / \mathrm{L})$ & LOQ $(\mu \mathrm{g} / \mathrm{L})$ & RSD for interday $(\%)$ & RSD for intraday $(\%)$ \\
\hline Chlorpyrifos & $Y=402 X+3.55 \times 10^{3}$ & 0.9991 & 0.0225 & 0.0964 & 1.97 & 2.98 \\
Fipronil & $Y=291 X-1.38 \times 10^{3}$ & 0.9996 & 0.0155 & 0.0565 & 1.44 & 3.17 \\
Procymidone & $Y=594 X+2.91 \times 10^{3}$ & 0.9993 & 0.0088 & 0.0354 & 1.63 & 3.82 \\
\hline
\end{tabular}

Therefore, the next step was to target quantifying the three pesticides using corresponding standard solution. The quantitative assay results of 40 batches of samples showed that only one batch detected chlorpyrifos at a level of $485.92 \mu \mathrm{g} / \mathrm{kg}$. Four batches of samples were detected with fipronil in the range of $28.62 \mu \mathrm{g} / \mathrm{kg}$ to $193.12 \mu \mathrm{g} / \mathrm{kg}$. It was worth noting that a total of 29 batches of samples detected procymidone, and the content of procymidone in CX19 was almost 131-fold higher than this in CX10 (3712.16 vs. $28.25 \mu \mathrm{g} / \mathrm{kg})$. This result indicated that the use of procymidone in the planting process of chuanxiong rhizoma has become more common, and the residue amount of procymidone in Ligusticum chuanxiong Hort was very serious. Therefore, it is necessary to continuously monitor the residual amount of procymidone in chuanxiong rhizoma to ensure the safety of the clinical use of this herb. Typical mass chromatograms of procymidone, chlorpyrifos, and fipronil in chuanxiong rhizoma samples solution are displayed in Figure 4. The detailed results are summarized in Table 3.

3.6. Validation of the GC-MS/MS Method. During the experiment, linearity, precision, sensitivity, stability, and accuracy analyses were completed to evaluate the newly established analysis approach. Linear regression equations of the three target pesticide compounds were acquired at six concentration levels in triplicate, and the LODs and LOQs of the three pesticides were optimized for subsequent analysis (see Table 4). The RSD values for interday and intraday variation were acquired to evaluate the precision of the analytical approach, and the overall inter- and intraday variations are not more than $1.97 \%$ and $3.82 \%$, respectively (see Table 4). The variations of concentrations of the analyzed three pesticide compounds in sample CX16 are $0.74 \%-4.15 \%$, indicating that the three pesticides in the sample solutions were maintained stable in $48 \mathrm{~h}$. The spiked recoveries of the three pesticides are $95.22 \%, 93.03 \%$, and $94.31 \%$, and the RSDs were less than $\pm 6.0 \%$. The methodological verification results indicated the good reliability and accuracy of the new analytical method.

\section{Conclusions}

In this exemplary research, a very practical GC-MS/MS analytical approach for 74 pesticide residues in chuanxiong rhizoma herb based on the retention index was established. This novel analytical approach has two important applications. One was to rapidly screen out the multipesticides in herbal medicines without having to use a large number of standard substances at the beginning of the experiment. The other important application was to assist accurately in qualitative target pesticide compound. This new analytical approach can increase pesticide analysis efficiency and significantly reduce the cost of analysis. This research was a new application of the retention index, and it will be a valuable tool for quickly and accurately quantifying the analysis of multipesticide residues in traditional herbal medicines.

\section{Data Availability}

The underlying data supporting the results of our study can be found in the manuscript.

\section{Conflicts of Interest}

The authors declare they have no conflicts of interest.

\section{Acknowledgments}

This work was supported by the National Natural Science Foundation of China (Grant no. 81703820), Sichuan Provincial Department of Science and Technology Key Research and Development Projects (Grant nos. 2018ZX09201018029, 2018SZ0056, and 2019YJ0640), and Chengdu Science and Technology Bureau Foundation (Grant no. 2018-YF0501277-SN).

\section{Supplementary Materials}

Table S1: monitoring ion pairs and collision energy of 74 pesticide compounds. Table S2: quantitative analysis methodological results of the three target pesticides compounds that were screened. (Supplementary Materials)

\section{References}

[1] J. Xiao, X. Xu, F. Wang et al., "Analysis of exposure to pesticide residues from traditional Chinese medicine," Journal of Hazardous Materials, vol. 365, pp. 857-867, 2019.

[2] J.-J. Xiao, J.-S. Duan, X. Xu et al., "Behavior of pesticides and their metabolites in traditional Chinese medicine Paeoniae Radix Alba during processing and associated health risk," Journal of Pharmaceutical and Biomedical Analysis, vol. 161, pp. 20-27, 2018.

[3] L. Chen, F. Song, Z. Liu, Z. Zheng, J. Xing, and S. Liu, "Study of the ESI and APCI Interfaces for the UPLC-MS/MS analysis of pesticides in traditional Chinese herbal medicine," Analytical and Bioanalytical Chemistry, vol. 406, no. 5, pp. 1481-1491, 2014.

[4] G. Du, Y. Xiao, H.-R. Yang, L. Wang, Y.-L. Song, and Y.-T. Wang, "Rapid determination of pesticide residues in herbs using selective pressurized liquid extraction and fast gas chromatography coupled with mass spectrometry," Journal of Separation Science, vol. 35, no. 15, pp. 1922-1932, 2012. 
[5] S. M. Taha and S. A. Gadalla, "Development of an efficient method for multi residue analysis of 160 pesticides in herbal plant by ethyl acetate hexane mixture with direct injection to GC-MS/MS," Talanta, vol. 174, pp. 767-779, 2017.

[6] N. Besil, S. Uclés, M. Mezcúa, H. Heinzen, and A. R. Fernández-Alba, "Negative chemical ionization gas chromatography coupled to hybrid quadrupole time-of-flight mass spectrometry and automated accurate mass data processing for determination of pesticides in fruit and vegetables," Analytical and Bioanalytical Chemistry, vol. 407, no. 21, pp. 6327-6343, 2015.

[7] W. Zheng, J.-A. Park, A. M. Abd El-Aty et al., "Development and validation of modified QuEChERS method coupled with LC-MS/MS for simultaneous determination of cymiazole, fipronil, coumaphos, fluvalinate, amitraz, and its metabolite in various types of honey and royal jelly," Journal of Chromatography B, vol. 1072, pp. 60-69, 2018.

[8] L. Zhao, T. Szakas, M. Churley, and D. Lucas, "Multi-class multi-residue analysis of pesticides in edible oils by gas chromatography-tandem mass spectrometry using liquidliquid extraction and enhanced matrix removal lipid cartridge cleanup," Journal of Chromatography A, vol. 1584, pp. 1-12, 2019.

[9] C.-C. Wu, "Multiresidue method for the determination of pesticides in Oolong tea using QuEChERS by gas chromatography-triple quadrupole tandem mass spectrometry," Food Chemistry, vol. 229, pp. 580-587, 2017.

[10] F. Huo, H. Tang, X. Wu et al., "Utilizing a novel sorbent in the solid phase extraction for simultaneous determination of 15 pesticide residues in green tea by GC/MS," Journal of Chromatography B, vol. 1023-1024, pp. 44-54, 2016.

[11] C. R. Tarley, F. A. Suquila, J. Casarin et al., "Development of selective preconcentration/clean-up method for imidazolinone herbicides determination in natural water and rice samples by HPLC-PAD using an imazethapyr imprinted poly (vinylimidazole-TRIM)," Food Chemistry, vol. 334, Article ID $127345,2020$.

[12] Z. Tang, Z. Chen, G. Li, and Y. Hu, "Multicolor nitrogen dots for rapid detection of thiram and chlorpyrifos in fruit and vegetable samples," Analytica Chimica Acta, vol. 1136, pp. 72-81, 2020.

[13] M. D. Fernández-Ramos, A. L. Ogunneye, N. A. A. Babarinde, M. M. Erenas, and L. F. Capitán-Vallvey, "Bioactive microfluidic paper device for pesticide determination in waters," Talanta, vol. 218, Article ID 121108, 2020.

[14] E. Kováts, "Gas-chromatographische Charakterisierung organischer Verbindungen. Teil 1: retentionsindices aliphatischer Halogenide, Alkohole, Aldehyde und Ketone," Helvetica Chimica Acta, vol. 41, no. 7, pp. 1915-1932, 1958.

[15] J. Zhang, A. Fang, B. Wang et al., "iMatch: a retention index tool for analysis of gas chromatography-mass spectrometry data," Journal of Chromatography A, vol. 1218, no. 37, pp. 6522-6530, 2011.

[16] I. Koo, X. Shi, S. Kim, and X. Zhang, "iMatch2: compound identification using retention index for analysis of gas chromatography-mass spectrometry data," Journal of Chromatography A, vol. 1337, pp. 202-210, 2014.

[17] S. Kumari, D. Stevens, T. Kind, C. Denkert, and O. Fiehn, "ApplyingIn-SilicoRetention index and mass spectra matching for identification of unknown metabolites in accurate mass GC-TOF mass spectrometry," Analytical Chemistry, vol. 83, no. 15, pp. 5895-5902, 2011.
[18] W. Guo, Y. Lu, and X. M. Zheng, “The Predicting study for chromatographic retention index of saturated alcohols by MLR and ANN," Talanta, vol. 51, no. 3, pp. 479-488, 2000.

[19] V. V. Mihaleva, H. A. Verhoeven, R. C. H. de Vos, R. D. Hall, and R. C. H. J. van Ham, "Automated procedure for candidate compound selection in GC-MS metabolomics based on prediction of Kovats retention index," Bioinformatics, vol. 25, no. 6, pp. 787-794, 2009.

[20] N. Strehmel, J. Hummel, A. Erban, K. Strassburg, and J. Kopka, "Retention index thresholds for compound matching in GC-MS metabolite profiling," Journal of Chromatography B, vol. 871, no. 2, pp. 182-190, 2008.

[21] P. Tan, X. Wei, H. Zhang, M. Niu, and D. Zhang, "A practical method for rapid screening and quantitative analysis of 130 pesticide residues in herbal medicines based on the Kovats retention index principle: an exemplary study using Panacis quinquefolii radix," Analytical Methods, vol. 11, no. 38, pp. 4868-4874, 2019.

[22] L. Li, H. Chen, A. Shen et al., "Ligustrazine inhibits platelet activation via suppression of the Akt pathway," International Journal of Molecular Medicine, vol. 43, no. 1, pp. 575-582, 2019.

[23] L. Chen, T. Liu, Q. Wang et al., "Anti-inflammatory effect of combined tetramethylpyrazine, resveratrol and curcumin in vivo," BMC Complementary and Alternative Medicine, vol. 17, no. 1, p. 233, 2017.

[24] A. Wang, G. Zhu, P. Qian, and T. Zhu, "Tetramethylpyrazine reduces blood-brain barrier permeability associated with enhancement of peripheral cholinergic anti-inflammatory effects for treating traumatic brain injury," Experimental and Therapeutic Medicine, vol. 14, no. 3, pp. 2392-2400, 2017.

[25] P. Zhou, S. Du, L. Zhou et al., "Tetramethylpyrazine-2'O-sodium ferulate provides neuroprotection against neuroinflammation and brain injury in $\mathrm{MCAO} / \mathrm{R}$ rats by suppressing TLR-4/NF- $\kappa$ B signaling pathway," Pharmacology Biochemistry and Behavior, vol. 176, pp. 33-42, 2019.

[26] Z. Shao, P. Wu, X. Wang et al., "Tetramethylpyrazine protects against early brain injury and inhibits the PERK/Akt pathway in a rat model of subarachnoid hemorrhage," Neurochemical Research, vol. 43, no. 8, pp. 1650-1659, 2018. 